\title{
Ocena jakości połączeń spawanych przez analizę logarytmicznego rozkładu wartości średnich widm amplitudowych obliczanych metodą okien czasowych
}

\author{
Quality assesment of welded joints \\ using the logarithmic distribution analysis of amplitude spectrums \\ calculated time window method
}

\section{Streszczenie}

W systemach ciągłego monitoringu połączeń spawanych konstrukcji cienkościennych, najbardziej obiecującą jest metoda wibrodiagostyczna. Najważniejszą jej zaletą jest to, że jest efektywna i stwarza największe możliwości badań w czasie rzeczywistym. W pracy zastosowano metodę pomiarów charakterystyk dynamicznych konstrukcji przy pomocy czujników piezoelektrycznych. W artykule przedstawiono założenia oceny połączeń spawanych z wykorzystaniem analizy logarytmicznego rozkładu wartości średniej widm amplitudowych obliczanych metodą okien czasowych. Wykorzystana miara statystyczna w postaci wartości średniej jest propozycją parametru, którego analiza dla danego połączenia spawanego może pozwolić na jednoznaczną ocenę jego jakości. Zwrócono uwagę na istotne dla badania elementy, przedstawiono algorytm obliczeniowy oraz przykładowe wyniki z aplikacji proponowanej metody do kilku wybranych płyt spawanych z różnymi rodzajami wad. Z przeprowadzonych badań wynika, że analiza rozkładów wartości średnich dla widm amplitudowych obliczonych metodą okien czasowych wskazuje, że różnią się one między sobą w zależności od spawów, wskazując na ich jakość i wady, które są z nimi związane.

Słowa kluczowe: diagnostyka; połączenia spawane; badania nieniszczące; NDT; SHM; drgania; analiza widmowa; okna czasowe; wartość średnia

\begin{abstract}
In continuous monitoring systems of welded joints of thinwalled structures, a vibrodiagnostic method is the most promising. Its most important advantage is that it is effective and offers the greatest real-time research capabilities. It is used in classic NDT techniques as well as in construction monitoring during operation. This work presents a measurement method of dynamic characteristics of the structure with the use of piezoelectric sensors. The article presents the assumptions concerning the evaluation of welded joints using the analysis of the logarithmic distribution of the amplitude spectrums calculated by the time window method. The statistical measure used in the form of the mean value is a proposed parameter, which analysis for a given welded joint may enable an unambiguous assessment of its quality. Attention was paid to the elements important for the study and they included a calculation algorithm and the sample results from the proposed method used for some selected plates with different welds. The work contains the description of the stand to register dynamic characteristics in case of welded joints. The results of the tests show that the analysis of the logarithmic distribution value for amplitude spectrums calculated by the time window method indicates that they differ markedly depending on the welds, indicating their quality and defects which are associated with them.
\end{abstract}

Keywords: diagnostics; welded joints; non-destructive testing; NDT; SHM; vibration; spectrum analysis; time window; mean value

\begin{abstract}
Wstęp
Badania nieniszczące NDT (ang. Non-Destructive Testing) są badaniami, dzięki którym można uzyskać informacje o stanie, właściwościach i ewentualnych wadach obiektu bez ingerowania w jego cechy użytkowe i strukturę. Badania te przeprowadzane są między innymi w złączach spawanych, połączeniach klejonych, zgrzewanych, lutowanych, odlewach, elementach wykonanych z materiałów kompozytowych $[1,2]$.
\end{abstract}

Wykorzystywane są one w procedurach oceny niezawodności oraz jakości produktów będących w trakcie procesu technologicznego, gotowych oraz eksploatowanych. Badania NDT stosowane są w celu osiągnięcia odpowiednio wysokiego poziomu jakości i bezpieczeństwa. Powodem korzystania z badań nieniszczących jest określenie rodzaju, wielkości i miejsca występowania niezgodności w celu

Mgr inż. Adam Szeleziński, dr inż. Adam Muc, dr hab. inż. Lech Murawski- Akademia Morska w Gdyni.

Autor korespondencyjny/Corresponding author. a.szelezinski@wm.am.gdynia.pl 
stwierdzenia ich dopuszczenia lub konieczności usunięcia z badanego elementu. Istotną cechą badań NDT jest możliwość określenia właściwości oraz uzyskanie opisu fizyczne-

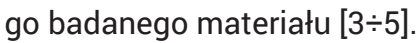

Czynności kontrolne zapewniające jakość złączy spawanych znajdują miejsce nie tylko w trakcie procesu produkcji, ale także w celu diagnozowania eksploatowanej konstrukcji. Mają one na celu uniknięcie niespodziewanych uszkodzeń obiektów technicznych przez wyłączanie z pracy obiektów z uszkodzeniami eksploatacyjnymi powodującymi zagrożenie dla bezpieczeństwa podczas dalszego użytkowania. Brak wykonywania eksploatacyjnych badań nieniszczących obiektów technicznych (np. samolotów, statków, urządzeń dźwigowych, mostów itp.) bądź przeprowadzanie ich niezgodnie z procedurami może prowadzić do katastrof i awarii $[4,6,7]$.

Nowoczesne systemy monitoringu stanu konstrukcji SHM (ang. Structural Health Monitoring) opierają się częściowo na metodach badań nieniszczących, które wykorzystywane są podczas przeprowadzania okresowych inspekcji konstrukcji spawanych w miejscach dużego prawdopodobieństwa wystąpienia wad. Główna różnica między SHM a NDT wynika z architektury sprzętowej [8]. W systemach SHM sieć czujników jest zintegrowana z obiektem, natomiast w przypadku NDT mamy do czynienia z zewnętrzną, niezależną siecią czujników. Układy SHM działają (diagnozują w czasie rzeczywistym) „on-line" w przeciwieństwie do technik NDT. Istotnym elementem systemów SHM jest zautomatyzowanie ich działania (np. generowanie raportów, informowanie obsługi o niestandardowych parametrach) w oparciu o techniki sztucznej inteligencji $[7,8]$.

Na szybki rozwój i powszechne stosowanie badań NDT w technice ma wpływ dużo czynników. Najważniejsze z nich to bezpieczeństwo i ekonomia. W rozwoju badań nieniszczących dominuje tendencja do uzyskania jak największej ilości informacji o stanie jakości badanego elementu w celu wykrywania jeszcze mniejszych wad. Rozwój ten dąży także do zwiększenia szybkości wykonywania badań oraz zwiększenia bezpieczeństwa i ograniczenia szkodliwego oddziaływania środków używanych do badań na zdrowie operatorów. Rozwój dotyczy zarówno dotychczas używanych metod i ich zastosowań, jak i nowo wprowadzanych.

Operatorzy badań nieniszczących realizujący je w przemyśle, korzystają z sześciu podstawowych metod badań NDT: wizualnych (VT), penetracyjnych (PT), magnetyczno-proszkowych (MT), radiograficznych (RT), ultradźwiękowych (UT) i prądów wirowych (PT) [1,2]. Każda z wymienionych powyżej metod cechuje się pewnymi ograniczeniami, które omówiono w artykule [9]. Nowoczesne metody badań NDT np. emisja akustyczna, termografia, wibrotermografia, metody bazujące na czujnikach światłowodowych oraz połączenia tych metod z konwencjonalnymi są wykorzystywane podczas diagnostyki obiektów o szczególnym przeznaczeniu. $Z$ reguły wykonywane są przez pracowników ośrodków badawczych lub wyspecjalizowanych i akredytowanych laboratoriów, którzy posiadają specjalistyczną wiedzę oraz niezbędne doświadczenie [11].

Autorzy przeprowadzili badania wstępne, których celem było sprawdzenie możliwości wykorzystania wibrodiagno-

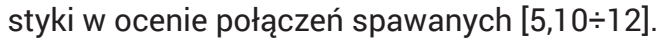

\section{Metoda i warunki pomiaru}

Na potrzeby prowadzonych prac zostało zbudowane stanowisko, które umożliwia wibrodiagnostyczne badanie połączeń spawanych. W skład stanowiska wchodzą: stojak, w którym mogą być montowane płyty (próbki spawalnicze) w sposób poziomy - mocowanie cztero punktowe lub pionowy - mocowanie dwu punktowe, analizator drgań firmy Bruel \& Kjear typu 3050-A-60, dwa akcelerometry 4514-B i młotek modalny (8206-002) z trzema wymiennymi końcówkami, tj. metalową, silikonową i teflonową.

Badania zostały przeprowadzone na czterech płytach. Jedna z nich oznaczona została numerem "0" i była płytą bez połączenia spawanego. Trzy kolejne, były płytami spawanymi i oznaczono je następującymi numerami: 2202 - płyta z połączeniem spawanym bez wad w spoinie, 2127 - płyta spawana z wadą typu przyklejenie brzegowe w spoinie i 2132 - płyta spawana z wadą typu pęknięcie o zdefiniowanej długości w spoinie. Wszystkie próbki posiadające połączenia spawane przed użyciem ich do pomiarów zostały przebadane metodą radiograficzną (rys. 1). Pozwoliło to na ocenę jakości połączeń oraz umożliwiło identyfikację i umiejscowienie niezgodności w płytach.

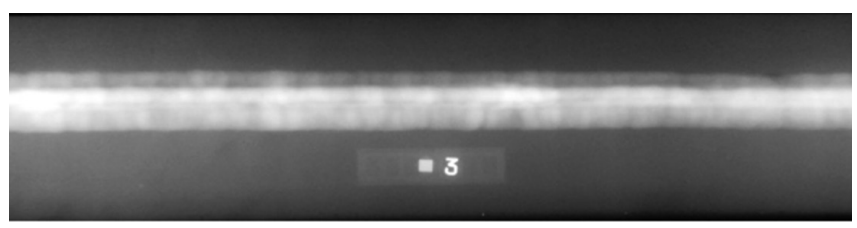

Rys. 1. Zdjęcie radiograficzne połączenia spawanego - płyta spawana bez wad w spoinie (2202)

Fig. 1. Radiography of welded joint - welded plate without defects in the weld (2202)

W przygotowanym stanowisku badawczym przeprowadzono pomiary drgań generowanych przez płyty. Drgania wywołane były przez uderzenie młotkiem modalnym z różnymi końcówkami: metalową, silikonową i teflonową. Miejsca uderzeń zostały przedstawione na rysunku 2 za pomocą oznaczeń: F1, F2 i F3. Wyniki były odczytane przez akcelerometry ACC1 i ACC2.

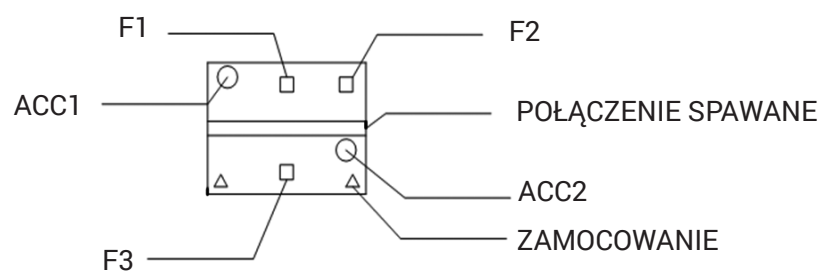

Rys. 2. Poglądowy rysunek przedstawiający rozmieszenie akcelerometrów ACC1 i ACC2 w miejscach uderzeń: F1, F2, F3, oraz miejsca zamocowania płyty w uchwytach stojaka $(\Delta)[10]$

Fig. 2. An overview of $A C C 1$ and $A C C 2$ accelerometers at the points of impact: F1, F2, F3, and the mounting locations of the plates in the rack holders $(\Delta)[10]$

\section{Metoda okien czasowych w analizie czasowo-częstotliwościowej}

Metoda okien czasowych umożliwia równoczesną analizę sygnałów w dziedzinie częstotliwości i czasu. Możliwość ta jest często wykorzystywana w analizie dynamiki systemów technicznych, a szczególnie elektrycznych lub elektronicznych. Znacznie rzadziej wykorzystuje się ją do badania systemów mechanicznych. W metodzie okien czasowych kluczowym elementem, który rzutuje na jakość uzyskanych wyników, jest właściwy dobór typu i szerokości okna czasowego. Następnie, dla każdego okna przeprowadzana jest analiza FFT (ang. Fast Fourier Transform). 
W prowadzonych badaniach wykorzystano metodę okien czasowych do analizy odpowiedzi zarejestrowanymi akcelerometrami, które zostały rozmieszczone na płytach z połączeniami spawanymi. Badania zostały przyprowadzone dla okna prostokątnego, dla którego były testowane różne interwały czasowe. Okno prostokątne zostało wybranego głównie dlatego, aby w jak najmniejszym stopniu ograniczyć zniekształcenia zarejestrowanych przebiegów odpowiedzi. Taka sytuacja ma często miejsce przy bardziej wyszukanych oknach. Wówczas, za cenę akceptowanych zmian wprowadzonych od sygnału można przez okno wyeliminować część zakłóceń.

Przeprowadzone badania testowe miały na celu jak najlepsze uwzględnienie charakterystycznych zmian w widmach, które świadczą o jakości spawów i ewentualnych wadach. Ostatecznie jednak dobrano szerokość okna o wartości $10 \mathrm{~ms}$.

Obliczenia wykonano dla płyty bez spawu i z 3 rodzajami wad w połączeniu spawanym. Dla wszystkich płyt zarejestrowano akcelerometrami odpowiedź płyty na sygnał wywołany młotkiem modalnym z końcówką metalową i teflonową. Na rysunku 3 przedstawiono przykładowe zestawienie widm amplitudowych uzyskane dla końcówki metalowej i obliczone dla okien czasowych od numeru 1 do 12.

a)

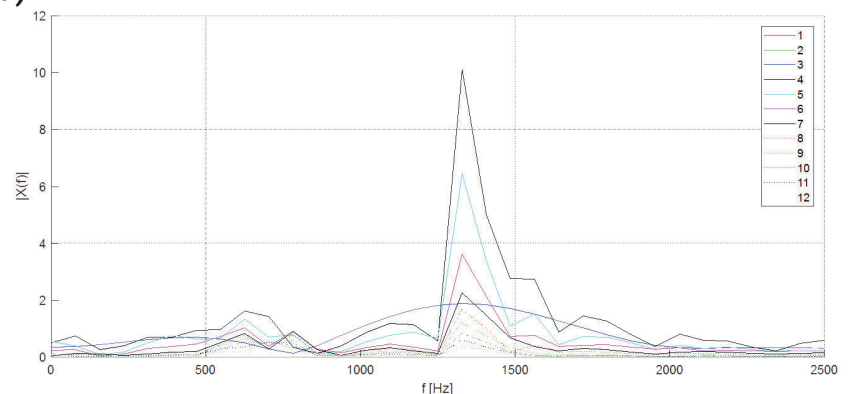

b)

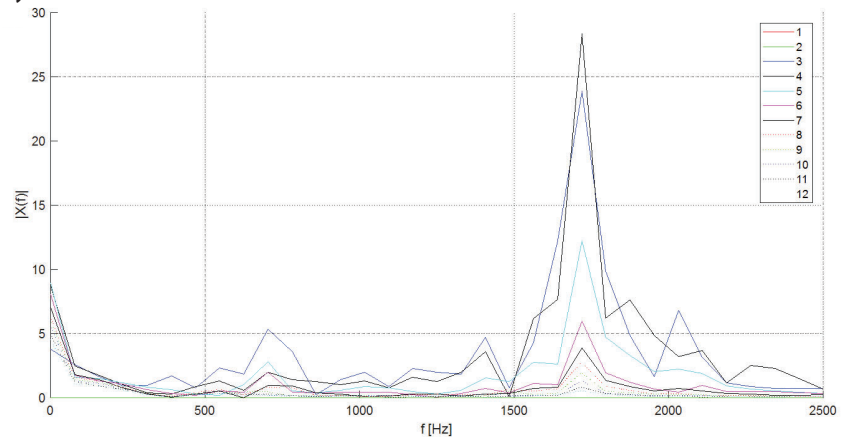

Rys. 3. Widma amplitudowe obliczone metodą okien czasowych dla płyty spawanej: a) bez wad w spoinie (2202), b) z wadą typu przeklejenie brzegowe (2127)

Fig. 3. Amplitude spectra calculated by the time window method for a welded plate: a) without defects in the weld (2202), b) with the lack of side fusion (2127)

Analiza porównawcza widm amplitudowych obliczonych dla poszczególnych okien uwidacznia nieliniowości struktur uszkodzonych płyt spawanych. Nieliniowości te są tym mocniejsze im połączenie spawane jest gorszej jakości, tj. gdy ujawni się w nim wada w spoinie. W prezentowanym przykładzie (rys. 3) sytuacja taka dotyczy płyty spawanej z wadą typu przeklejenie brzegowe. Ze wstępnej analizy widm widać również, że najwięcej informacji diagnostycznych niesie pierwszych dziesięć okien czasowych, czyli jest to ok. $100 \mathrm{~ms}$ analizowanej odpowiedzi zarejestrowanej akcelerometrem. Widma amplitudowe prezentowane na rysunku 3 charakteryzują się podobnym charakter rozkładu, zwłaszcza w odniesieniu do znaczących harmonicznych, natomiast istotną informację diagnostyczną niosą widma o wyższych harmonicznych, których analiza wymaga już dodatkowych przekształceń matematycznych.

\section{Rozkłady wartości średniej widm amplitudowych i zastosowanie ich do oceny połączeń spawanych}

W celu porównania widm amplitudowych obliczanych dla poszczególnych okien tej samej próbki oraz do oceny nieliniowości wynikającej z powstania spoiny spawanej w płycie, zaproponowano parametr, którym jest wartość średnia. Wartość średnia jest miarą statystyki opisowej, którą obliczono na podstawie równania (1).

$$
\overline{|v|}=\frac{\sum_{i=0}^{N}\left|v\left(f_{i}\right)\right|}{N}
$$

gdzie:

$|\mathrm{v}|$ - średnia wartość widma amplitudowego prędkości v obliczona dla okna czasowego,

$\mathrm{f}_{\mathrm{i}}$ - częstotliwość i-tej harmonicznej,

$\mathrm{N}$ - liczba harmonicznych.

Jak pokazały badania wstępne, analiza jedynie wartości średnich jest niewystarczająca. Natomiast istotnej informacji diagnostycznej o jakości połączenia spawanego dostarcza rozkład wartości średniej dla widm uzyskanych z okien czasowych całej odpowiedzi. Na rysunku 4 przedstawiono przykładowe widma amplitudowe pochodzące z wybranych okien czasowych i obliczone dla nich wartości średnie.

Przedstawiony na rysunku 5 rozkład przedstawia zmianę wartości średniej obliczonej dla widma amplitudowego w danym oknie w funkcji numeru okna dla danej płyty spawanej. Na prezentowanych charakterystykach widać, że rozkład wartości średniej dla okien obliczonych dla próbki bez spawu (oznaczona: 0) znacząco różni się w stosunku do rozkładu wartości średnich pozostałych próbek ze spawem bez wad w spoinie (2202) lub wadami w spoinie (oznaczone: 2132, 2127).
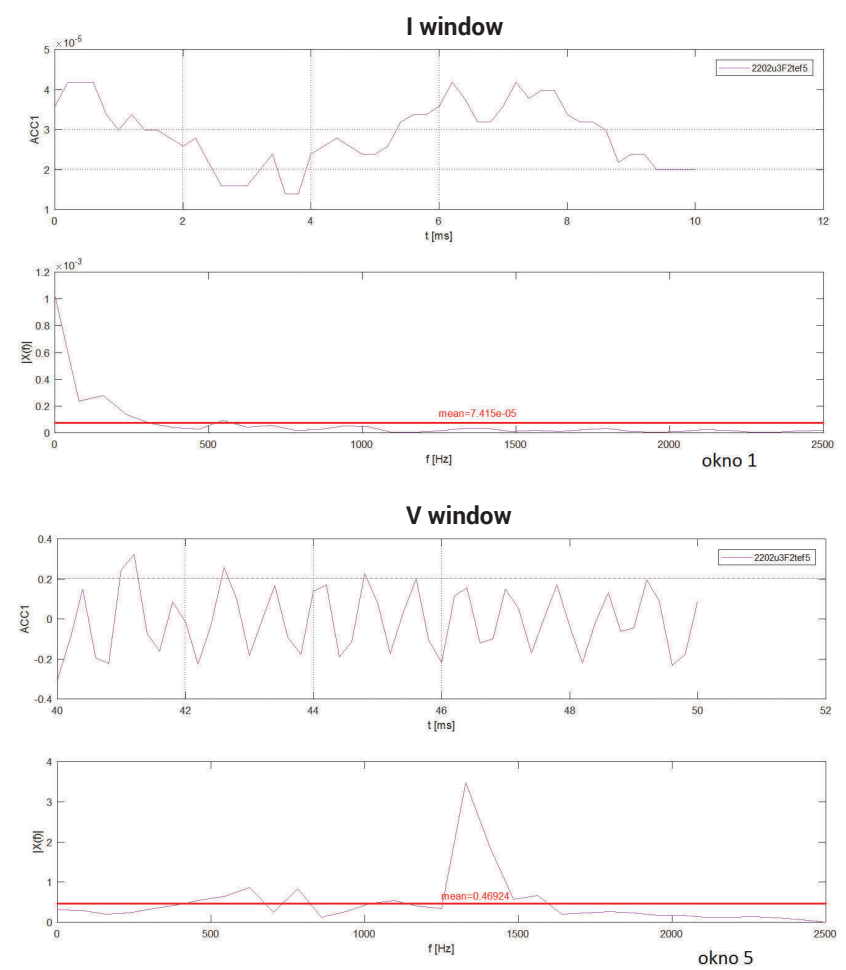

Rys. 4. Widma amplitudowe wybranych okien z oznaczoną wartością średnią

Fig. 4. Amplitude spectra of selected windows with the average value 
Jak wynika z rysunku 5 , w przypadku płyt spawanych liniowe rozkłady wartości średnich nie wykazują znacznych różnic wizualnych, dlatego przedstawienie ich w skali logarytmicznej pozwala na ich uwypuklenie. Różnice te dotyczą szczególnie poziomu wartości średnich i cyklicznej

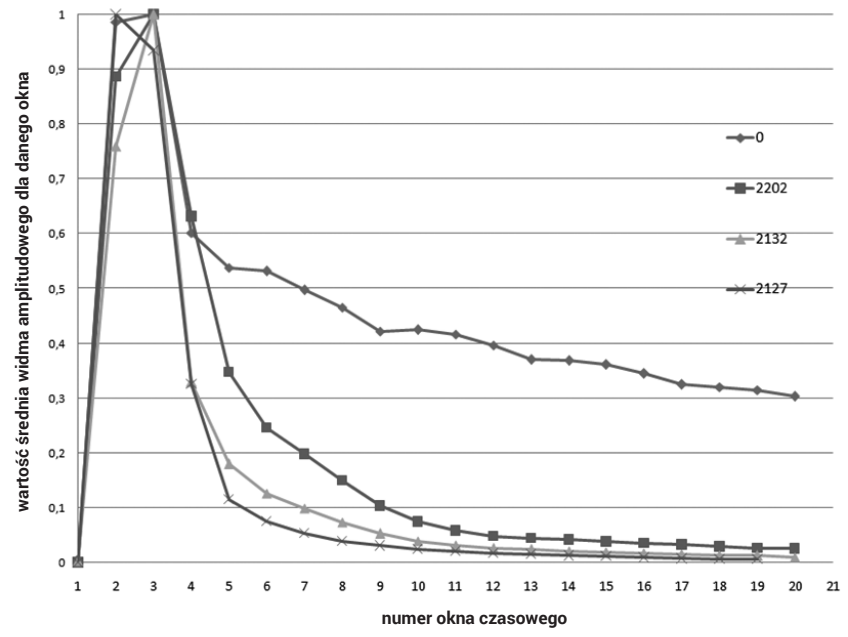

Rys. 5. Rozkład wartości średnich widm dla okien w funkcji numeru okna dla badanych płyt, gdzie: 0 - płyta bez połączenia spawanego, 2202 - płyta z połączeniem spawanym bez wady w spoinie, 2132 - płyta $z$ połączeniem spawanym typu pęknięcie $w$ spoinie, 2127 - płyta z połączeniem spawanym typu przeklejenie brzegowe w spoinie

Fig. 5. Distribution of average spectral values for windows as a function of window number for tested boards, where: 0 - plate without welded joint, 2202 - plate with a welded joint without defect in the joint, 2132 - plate with a welded joint with the weld crack, 2127 - plate with a welded joint with the lack of side fusion zmiany wartości między lokalnymi maksimami i minimami. Na przedstawionych rozkładach z rysunku 6 można już zauważyć, że rozkłady wartości średnich dla płyty spawanej bez wady w spoinie i z wadami charakteryzują się wyraźnie różnymi w tych rozkładach.

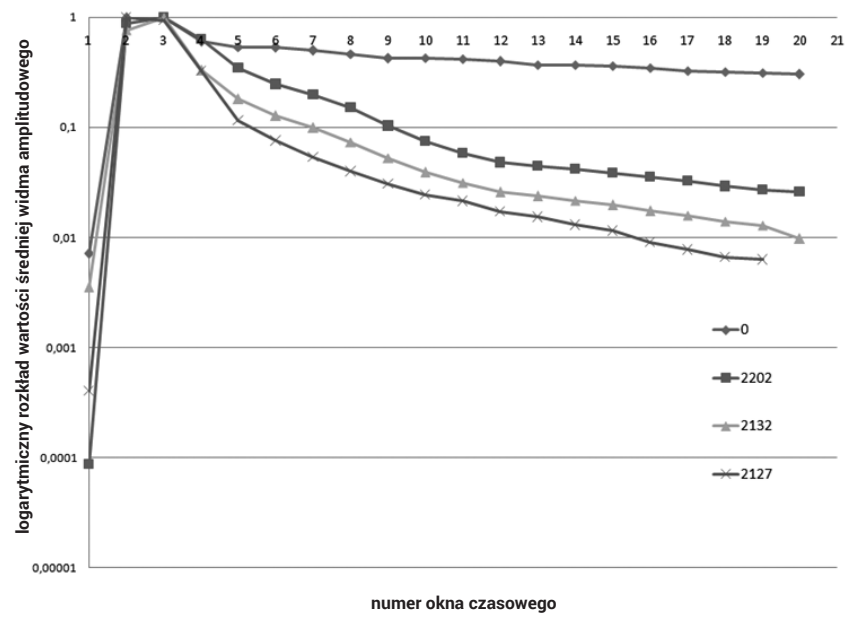

Rys. 6. Logarytmiczny rozkład wartości średnich widm dla okien w funkcji numeru okna dla badanych płyt, gdzie: 0 - płyta bez połączenia spawanego, 2202 - płyta z połączeniem spawanym bez wady w spoinie, 2132 - płyta z połączeniem spawanym typu pęknięcie w spoinie, 2127 - płyta z połączeniem spawanym typu przeklejenie brzegowe w spoinie

Fig. 6. Logarithmic distribution of average spectral values for windows as a function of window number for tested boards, where: 0 - plate without welded joint, 2202 - plate with a welded joint without defect in the joint, 2132 - plate with a welded joint with the weld crack, 2127 - plate with a welded joint with the lack of side fusion

\section{Wnioski}

Informacje diagnostyczne uzyskane w wyniku analizy rozkładu wartości średnich widm obliczonych dla okien czasowych dla danej płyty z połączeniem spawanym, umożliwia wnioskowanie o stanie i jakości spoiny. Analiza takich charakterystyk stwarza możliwość zastosowania ich do detekcji uszkodzeń w spawach w systemach do automatycznego monitoringu konstrukcji typu SHM.

Wykorzystanie do oceny połączeń spawanych metody okien czasowych pozwoliło analizować odpowiedzi z akcelerometrów zarówno w dziedzinie czasu, jak i częstotliwości. Wszelkie różnice charakterystyk częstotliwościowych w poszczególnych oknach czasowych świadczą o nieliniowości układu, a więc i o dodatkowej dyssypacji energii drgań świadczącej o niespójności konstrukcji. Dodatkowa dyssypacja natomiast wskazuje na niedoskonałość połączenia spawanego.

Proponowana metoda oceny połączeń spawanych wymaga dalszych badań na większej licznie próbek z różnymi wadami spoiny spawanej.

\section{Literatura}

[1] Czuchryj J.: Badanie złączy spawanych wg. norm europejskich. Systematyka i przyczyny postania wad w złączach spawanych, Biuro Gamma, Warszawa, 2003.

[2] Lewicka-Romicka A.: Badania nieniszczące. Podstawy defektoskopii, Wydawnictwo Naukowo - Techniczne, Warszawa, 2001.

[3] Dudzik S.: Wyznaczenie głębokości defektów materiałowych z zastosowaniem aktywnej termografii dynamicznej i sztucznych sieci neuronowych, Wydawnictwo Politechniki Częstochowskiej, Częstochowa, 2013.

[4] Krajewski A., Hudycz M.: Zapewnienie jakości i kontrola złączy spajanych, Oficyna Wydawnicza Politechniki Warszawskiej, Warszawa, 2015.

[5] Szeleziński A., Muc A. , Murawski L.: Quality assesment of welded joints using the mean value distribution of amplitude spectrums calculated by the time window metod, Journal of KONES Powertrain and Transport, Vol. 24, No 2, European Science Society of Powertrain and Transport Publication, Warsaw, 2017, pp. 262-270.

[6] Bień J.: Uszkodzenia i diagnostyka obiektów mostowych, Wydawnictwo Komunikacji Łączności, Warszawa, 2010.

[7] Opoka S., Murawski L., Wandowski T., Malinowski P., Ostachowicz W.: Static - Strain Level Change Together with Detection of Transient Signal as Damage Indicator for Truss and Fame Structures, Strain, Vol. 49 Issue 4, August, 2013, pp. 287-270.
[8] Murawski L., Ostachowicz W., Opoka S., Mieloszyk M., Majewska K.: Practical application of monitoring system based on optical sensors for marine constructions, Key Engineering Materials, Vol. 518, pp. 261-270, 2012.

[9] Szeleziński A., Gesella G., Murawski L.: Przegląd metod diagnostyki i monitoringu połączeń spawanych w konstrukcjach transportu morskiego, Logistyka, 3/2015 s. 4693-4702.

[10] Szeleziński A., Murawski L., Muc A., Gesella G.: Wybór końcówki młotka modalnego i miejsca uderzenia w badaniach metodą drganiową płyt spawanych, Zeszyty Naukowe Akademii Morskiej w Gdyni, nr 96, 2016, s. 179-191.

[11] Szeleziński A., Murawski L., Muc A.: Analysis of ability to detect defects in welding structures with usage of dynamic characteristics spectrums, Journal of KONES Powertrain and Transport, Vol. 23, No 2, European Science Society of Powertrain and Transport Publication, Warsaw, 2016, pp. 365-372.

[12] Szeleziński A., Muc A., Murawski L.: Analysis concerning changes of structure damping in welded joints diagnostics, Journal of KONES Powertrain and Transport, Vol. 24, No 4, European Science Society of Powertrain and Transport Publication, Warsaw, 2017, pp. 313-320. 